\title{
A FÍSICA PELOS PROFESSORES DE FÍSICA: A CONTRIBUIÇÃO DA TEORIA DAS REPRESENTAÇÕES SOCIAIS
}

\section{Physics by the teachers of Physics: the contribution of the Social Representation Theory}

\author{
Alcina Maria Testa Braz da Silva ${ }^{1}$ \\ Tarso Bonilha Mazzotti ${ }^{2}$
}

Resumo: A perspectiva da Psicologia Social, sob o enfoque da teoria das representações sociais, apresenta outro olhar para a discussão sobre as concepções alternativas dos estudantes. Neste intuito, retomo a análise dos principais resultados de uma pesquisa realizada no ano de 1996, na qual se identificaram os elementos que constituem o campo da representação do objeto social ciência física pelos professores que ministram essa disciplina no Ensino Médio. Na pesquisa foram realizadas 66 entrevistas semiestruturadas com professores de 17 escolas públicas na cidade do Rio de Janeiro. O referencial teórico/metodológico utilizado foi a análise categorial temática, com o suporte do programa de documentação de texto Data Collector (para HyperCard, Macintosh) e da abordagem das representações sociais. Os resultados apontaram a presença de dois polos de representação: i) realismo crítico, apoiado na visão contemporânea das ciências, ii) realismo ingênuo, correspondente à maioria dos entrevistados, sustentado em idéias intuitivas.

Palavras-chave: Ensino de Física. Concepções prévias. Representações sociais.

Abstract: The perspective of Social Psychology, approached from the social representations theory angle, introduces a new form of looking at the discussion about the students' alternative conceptions. With this in mind, I analyse the original results of research conducted in 1996, which identified the elements that compose the field of representation of the social aspect physical science by teachers who taught this subject to students of the secondary school level. In the afore mentioned research, 66 semi-structured interviews were made with teachers from 17 public schools of the city of Rio de Janeiro. The theory/methodology adopted was the thematic analysis of contents, with the support of the Data Collector (for HyperCard, Macintosh) software for text documentation and using the approach of the social representations. The outcomes of this research indicated the presence of two poles of representation: i) critical realism, based on a contemporary vision of the sciences, and ii) naive realism, which comprises the majority of the interviewed teachers, supported by intuitive ideas.

Keywords: Physics Education. Preconceptions. Social representations.

\footnotetext{
${ }^{1}$ Bacharel em Física, Doutora em Educação; Docente, Programa de Pós-graduação em Psicologia, Universidade Salgado de Oliveira. Niterói, RJ, Brasil. alcinamaria@terra.com.br.

${ }^{2}$ Licenciado em Pedagogia, Doutor em Educação; Docente, Universidade Estácio de Sá. Rio de Janeiro, RJ, Brasil.tarsomazzotti@uol.com.br

${ }^{1}$ Rua Marechal Deodoro, $217 / 2^{\circ}$ andar

Niterói - Centro - Rio de Janeiro, RJ

24.030-060 
Silva, A. M. T. B.; Mazzotti, T. B.

\section{Introdução}

O centro das investigações sobre o problema da ineficiência do ensino de Física nas escolas parte da constatação de que pessoas que receberam educação científica mantêm concepções pré-científicas. Dessa constatação surgiram numerosos trabalhos procurando inicialmente determinar o conteúdo das concepções pré-científicas e as razões pelas quais elas se mantêm. Estes trabalhos pressupõem que a permanência de concepções pré-científicas explica-se pela educação escolar que não as alterou ou as substituiu pelas científicas. As pesquisas seminais e independentes de Driver e Easley (1978) e Viennot (1979) deram origem a esta linha de pesquisa conhecida por mudança conceitual. As pesquisas desta linha têm, pelo menos, um ponto em comum: é necessário ultrapassar, de alguma maneira, as concepções prévias para que os estudantes apresentem ou desenvolvam as concepções próprias da ciência. No entanto, as propostas dos diversos autores têm sido muito diferentes quanto ao caráter da mudança pretendida, assim como em relação às estratégias a serem adotadas para alcançar: as que propõem a substituição de conceitos prévios e as que sugerem a reorganização daqueles conceitos. Estes autores focam suas atenções no conteúdo das ideias prévias dos estudantes ou no contexto no qual estes aplicam aquelas. Negligenciam, então, o eventual papel dos professores na produção e consolidação de concepções pré-científicas, uma vez que estes são considerados, aprioristicamente, os portadores dos conceitos científicos. Note-se que os "conceitos prévios" ou "espontâneos" são considerados "errados", justificando e reforçando a necessidade de substituí-los ou reorganizá-los.

Além disso, apesar de as pesquisas buscarem padrões ou tendências gerais das noções prévias com vistas a identificar algum compartilhamento na interpretação dos fenômenos, as explicações que apresentam, para a permanência daquelas noções, são particularistas e/ou individualistas. Isto porque não consideram que aquelas "concepções" são constituídas em um processo social que tem, na escola, um de seus focos. De fato, os autores que trabalham no campo da "mudança conceitual" consideram que os estudantes são os responsáveis diretos pelas falsas concepções.

Ultrapassar a limitação de base dos estudos sobre a permanência dessas concepções pré-científicas é o que pretendemos discutir neste trabalho. Para isto, recorremos à abordagem das “representações sociais” proposta por Moscovici (1978, 1981, 1984, 1988, 2001 e 2003). Procuraremos mostrar que esta abordagem é mais adequada para tratar das chamadas "concepções prévias". Isto será feito por meio da análise dos principais resultados de uma pesquisa, realizada no ano de 1996, sobre as representações sociais de Física, apresentada pelos professores desta disciplina nas escolas de Ensino Médio da cidade do Rio de Janeiro. Esta pesquisa representa uma primeira inserção na discussão psicossociológica da ciência Física enquanto objeto social, no caso para o grupo de referência professores de Física, assumindo a Teoria das Representações Sociais no cenário interfacial entre Ensino de Física e a Psicologia Social. Portanto, o regaste da análise desses resultados faz-se necessária.

\section{Representações sociais: o conceito e a teoria}

As representações sociais referem-se a um processo de constituição de saberes próprios de um grupo social e aos produtos daquele processo. Da perspectiva de Moscovici (1978), 
os atores sociais - no caso em pauta, os estudantes e professores - constituem suas representações de algum objeto que lhes interessa com base em suas práticas, nas conversações que mantêm entre si. De fato "algo" se põe como "objeto" aos atores sociais que constroem uma representação daquele "algo". Entre os temas, assuntos, postos como "objetos" aos membros de grupos sociais estão: as teorias, os conceitos, os artefatos os mais diversos. Os conceitos, teorias, artefatos e outras "coisas" produzidas pelas ciências e técnicas apresentam-se como algo que precisa ser incorporado no repertório de um grupo social por razões que o grupo mesmo dá para si. Assim, a novidade é assimilada e acomodada em seu repertório anterior, o qual, muitas vezes, é modificado para "receber" aquilo que se tornou objeto de conversações e, ao final, tem-se uma representação socialmente constituída.

Da perspectiva da teoria das representações sociais podemos sustentar que, no processo de escolarização, os professores são os agentes que apresentam "novidades" aos grupos sociais de alunos — classe ou turma —, os quais buscam assimilar estas "novidades" em suas redes de significações. Um conceito é assimilado e acomodado no que o grupo aluno já apresentava sobre o mesmo tema — queda dos corpos, por exemplo. Deste modo, é perfeitamente factível que os processos de assimilação e acomodação sejam produzidos por meio de desfalque, suplementação e distorção com vistas a não perturbar demasiadamente as representações que sustentam o grupo social (JODELET, 2001).

Gilly (2001) nos apresenta a discussão a respeito da relação entre as práticas sociais vigentes no campo educacional e as reconstruções de um objeto novo neste domínio. Segundo aquele autor, os fenômenos de descontextualização e recontextualização do saber, que ocorrem em cada etapa da transmissão social de um saber, envolvem processos de seleção e organização da informação que implicam a produção de representações sociais. Assim considerando, é preciso apreender o contexto histórico e social em que os sujeitos produzem e compartilham conhecimentos, em que se dá a negociação de significados. O que nos leva a sustentar que, no âmbito da educação escolar, a relação de ensino e aprendizagem requer um exame psicossocial. Isto porque os atores sociais põem-se como agentes da constituição de representações sociais de objetos próprios da educação escolar — teorias, conceitos, por exemplo - e constitui o que podemos denominar "saber escolarizado", o que examinaremos a seguir.

\section{Aprendizagem: um processo de produção de significados}

Do um ponto de vista epistemológico, o desenvolvimento histórico do conhecimento científico permite afirmar que as ciências se encontram em constante mudança em que nada pode ser considerado "como definitivamente estabelecido sobre as suas bases e protegido de qualquer modificação posterior” (PIAGET e GARCIA, 1987a, p. 22). As trajetórias das ciências, não são apenas de natureza contínua, nem implicam o predomínio de descontinuidades ou cortes epistemológicos, "ambos intervêm em todo o desenvolvimento" (PIAGET e GARCIA, 1987a). Não são trajetórias lineares, resultam justamente de um duplo movimento: continuidade e ruptura.

Como as ciências produzem conhecimentos confiáveis, eles são tomados por objeto pelos diversos grupos sociais que os apropriam em suas redes de significações produzindo representações sociais. Segundo Sá (1998), os princípios intuitivos de "espessura social" e "relevância cultural" de um objeto justificam a existência de representações implicadas "de 
Silva, A. M. T. B.; Mazzotti, T. B.

forma consistente, em alguma prática do grupo, ai incluída a da conversação e a da exposição aos meios de comunicação de massa" (SÁ, 1998, p. 50).

Assim, o exame das concepções constituídas e apreendidas na rede de significações dos indivíduos, em particular, e em situações que envolvem ensino-aprendizagem, ou seja, situações que mobilizam os atores sociais do cenário educacional em torno de objetos constituintes e constituidores deste cenário pode ser o caminho para investigar a geração e difusão de representações sociais acerca de tais objetos.

$\mathrm{Na}$ busca da constituição de uma pedagogia das ciências, que almeje a efetividade do ensino e aprendizagem dos conhecimentos científicos, é fundamental considerar as chamadas concepções alternativas apresentadas pelos estudantes. Busca-se o que poderia ser um ajustamento entre o que precisa ser apreendido pelo sujeito ingênuo e o que este sujeito apresenta. Assim sendo, não se pode ignorar a determinação da bagagem conceitual trazida pelos alunos, suas explicações sobre o mundo, suas representações do meio físico e social, as quais são resistentes às mudanças, como mostram as pesquisas sobre as concepções alternativas e as representações sociais. Para alcançar tal ajustamento, não é suficiente conhecer apenas as cognições dos estudantes, é necessário que as fontes de resistências sejam identificadas e, ao que parece, estão relacionadas às significações que os sujeitos estabelecem sobre as coisas e os fazeres (PIAGET e GARCIA, 1987a, 1987b). O ajustamento das cognições prévias dos estudantes aos conceitos apresentados pelas ciências requer o reconhecimento de um fato humano: os estudantes não são passivos receptores de mensagens, nem processadores de informação.

No entanto, a corrente da Psicologia Social conhecida por "teoria da cognição social" centra sua atenção nos processos psicológicos estritamente individuais, supondo que aquela cognição é um somatório destes processos. Tal teoria encontra-se na base das teorias sobre mudança conceitual. Vejamos o que a abordagem das representações sociais tem a dizer sobre isto.

Pela abordagem das representações sociais, a teoria da cognição social é criticada por sua exclusiva preocupação com o caráter individual das cognições, o que é característico da "assim chamada, psicologia social na América do Norte e Grã-Bretanha" (FARR apud SÁ, 1995, p. 20). A principal distinção entre a teoria da cognição social e a abordagem das representações sociais pode ser assim sumariada: a primeira procura explicar o desenvolvimento cognitivo com base apenas nas "competências cognitivas individuais" (DOISE, 2001, p. 303), enquanto a segunda procura expor os processos cognitivos engendrados nos meios sociais.

A pesquisa em representações sociais propõe uma mudança de foco da discussão concentrando-a nas teorias implícitas, nas peconcepções, nas imagens, estabelecendo a relação entre o pensamento científico e o senso comum com base na construção, compartilhamento e circulação das representações sociais. Essa mudança permite defender a ideia de que se o conhecimento do senso comum "serve muito bem a seus propósitos na vida diária", ele "não pode ser tão distorcido ou errado, como algumas vezes se supôs" (MOSCOVICI, 2003, p. 336). Na abordagem das representações sociais, as cognições não são tratadas como meras explicações erradas apresentadas pelo modo de pensar do indivíduo e este como produtor de um conhecimento desprovido de valor quando comparado com o conhecimento do especialista ${ }^{3}$. Ao contrário, considera que as representações são produzidas nas interações sociais, nas

\footnotetext{
${ }^{3} \mathrm{O}$ especialista, neste caso, é o conhecedor profissional, na acepção de Moscovici (2003), que, segundo se supõe, pauta o seu raciocínio pelas regras lógicas.
} 
conversações, afetando a maneira como interpretamos e avaliamos o entorno social e físico, as quais são verdadeiras para os membros do grupo ${ }^{4}$. De fato, o indivíduo não é um observador desinteressado ${ }^{5}$ uma vez que "lê" a realidade por meio de suas representações, que são socialmente construídas.

A distinção entre a teoria da cognição social e a das representações sociais quanto ao erro atribuído ao saber do conhecedor ingênuo é bastante instigante, pois, ao se discutirem as concepções alternativas dos estudantes em relação aos conceitos científicos, o que se evidencia, em toda literatura pertinente ao assunto, é a tendência de considerá-las erradas (POSNER et al , 1982; POSNER e STRIKE, 1982; STRIKE e POSNER, 1992; HEWSON e HEWSON, 1983; 1988; HASHWEH, 1986, entre outros), ou a possibilidade de estarem sendo aplicadas em contextos errados (DISESSA, 1982, 1983, 1985, 1988, 1993; SMITH, DISESSA e ROSCHELLE, 1993).

Um exemplo, no âmbito da Física, é a queda dos graves. Observa-se que os estudantes não se preocupam com este assunto. Caso examinemos as razões pelas quais tal tema não interessa aos alunos, verificamos que consideram, como muitas outras pessoas, que qualquer corpo cai necessariamente, logo, qual o valor, a importância de saber algo sob a queda dos graves? De fato, se é o peso que determina a queda, o corpo mais pesado cai mais depressa. Isto é lógico. Embora discutível, não é algo que se discuta nos contextos sociais usuais, mesmo na escola. Como este raciocínio não precisa ser invalidado no cotidiano do sujeito, então não se apresenta como um problema, não consiste em um desafio a ser superado. O que se tem, em situações de sala de aula, é a expressão da assimilação dos objetos à rede de significações apresentada pelo sujeito: este continua acreditando que o corpo mais pesado cai mais depressa e, ao realizar tarefas didáticas, aplica as fórmulas aprendidas conforme a exposição do professor, sem fazer diferença se está se tratando de um modelo, quais são as hipóteses que o sustentam, qual a sua relação com o que acontece empiricamente. Modificar este quadro é a intenção de diferentes estratégias identificadas na literatura pertinente às concepções alternativas e mudança conceitual, tanto por meio de uma mudança gradual quanto por uma mudança abrupta das ideias prévias do estudante.

Entretanto, as soluções apresentadas pelas principais tendências supõem que existe um raciocínio errado que precisa ser modificado, embora ele seja resistente à ação de modificação. Isso em nada resolve o problema da superação das concepções prévias. De fato, os autores se limitam a afirmar que tal ou qual conhecimento prévio expressa, por exemplo, o aristotelismo dos estudantes. Eles classificam os estudantes e desta categorização não se chega a lugar algum, a não ser à rotulação desse conhecimento com características depreciadoras, que reforça a necessidade de excluí-lo, ou por substituição ou por reorganização.

\footnotetext{
${ }^{4}$ Certamente, aqui se põe um problema grave da validação de conhecimentos científicos, não tratado neste artigo, para tanto sugerimos a leitura de Mazzotti e Oliveira (2000).

${ }^{5} \mathrm{O}$ termo empregado por Moscovici (1978) para caracterizar este observador é conhecedor amador. Em contraposição ao conhecedor ingênuo, o conhecedor amador apreende o conhecimento anteriormente elaborado de acordo com seus interesses pessoais. Neste processo adaptativo ele gera informações, prenhes de significados, buscando a compreensão do mundo que o rodeia.
} 
Silva, A. M. T. B.; Mazzotti, T. B.

O caminho apontado pela abordagem das representações sociais é muito diferente. Por ela, é fundamental considerar que as concepções que desenvolvemos o são em um contexto de conversação, logo em um grupo social mediato ou imediato. Assim, as concepções que se apresentam como falsas, erradas, do ponto de vista do grupo de cientistas, resultam de uma má adaptação dos conceitos aos fatos (MOSCOVICI, 2003). Conhecer as representações sociais de um determinado grupo e suas fontes de resistência é o que possibilitará construir as ultrapassagens no ensino do conhecimento científico.

Os estudantes do Ensino Médio têm contato sistemático com a Física por meio das aulas e, eventualmente, pelos livros didáticos, e é essa circunstância que lhes permite produzir uma representação daquela ciência, ou seja, ao se defrontarem com as teorias da Física que precisam ser assimiladas e acomodadas nas redes de significações que eles constituíram ao longo de suas relações com o ambiente físico e humano. Essa situação produz as representações dos conceitos daquela ciência, pois os estudantes lançam mão de seus recursos cognitivos e afetivos para apreenderem o que os professores e os livros didáticos apresentam. Nesse circuito os professores são os impulsionadores dos conhecimentos, desenvolvem um processo que permite a circulação de determinadas maneiras de se ver as ciências, particularmente a Física. Assim considerando, a investigação do que os professores pensam sobre as ciências é relevante para a compreensão das representações que circulam nas escolas. Tais representações podem constituir um obstáculo para a apreensão dos conceitos da Física, que é a ciência que nos interessa neste trabalho.

Nosso interesse é, portanto, a representação da Física e, de maneira implícita, as representações de ciências que os professores apresentam, assumindo que essas representações coordenam as demais, em particular as relações que os professores mantêm com seus alunos. Por certo não há uma determinação imediata entre a representação da Física e as práticas docentes, mas estas são organizadas, coordenadas e pensadas com base naquela representação. A representação social construída pelos professores permite, portanto, identificar suas decisões quanto ao que é legítimo ensinar, ao como ensinar, em que velocidade, e qual o tempo a ser dedicado a cada tema para se cumprir o programa curricular; por fim, permite compreender as razões de a Física ser ensinada desta ou daquela maneira.

\section{A representação social de Física por professores de Física}

Tendo em vista as argumentações apresentadas, descreveremos o desenvolvimento da pesquisa que objetivou conhecer os elementos da representação do objeto "ciência Física" apresentada pelos professores que ensinam essa disciplina no nível médio da rede de escolas mantidas pelos governos estadual e federal na cidade do Rio de Janeiro.

\section{Procedimentos}

Em uma primeira fase foi levantada, junto à Secretaria Estadual de Educação, a relação das escolas públicas do Estado. Dessas, separamos as que se localizam na cidade do Rio de Janeiro (121 escolas). Utilizamos os seguintes critérios, não hierárquicos e nem excludentes, na 
escolha das escolas que seriam visitadas: (a) pelo menos uma escola de cada coordenação administrativa; (b) escolas tanto com cursos de cultura geral, como as profissionalizantes; (c) preferência para as escolas que apresentassem os três turnos. Cruzando esses critérios selecionamos 15 escolas estaduais e duas técnicas federais, ou 17 escolas de Ensino Médio da cidade do Rio de Janeiro. Nesta pesquisa nos limitamos a recolher e analisar as entrevistas com os professores de Física com vistas a determinar os contornos da representação de Física apresentada por eles.

De posse do aval das instâncias competentes, e com os horários e turnos dos professores que estavam ministrando a disciplina Física, no ano letivo de 1996, realizamos um primeiro encontro. Inicialmente, expusemos os motivos de nossa presença na escola informando aos professores sobre o trabalho que estava sendo desenvolvido e convidando-os a participar de uma conversa sobre o assunto. Foram realizadas 66 entrevistas semiestruturas orientadas por três tópicos que alinhavaram a discussão. O primeiro referia-se ao livro didático, introduzindo a conversação sobre um assunto fortemente relacionado ao cotidiano dos professores. No livre desenvolvimento das entrevistas apareceram, na conversação estabelecida com o professor, os aspectos relativos aos alunos e, por estimulação, conversamos sobre o que entendiam por ciência Física e como esta é apresentada no Ensino Médio. É importante destacar que, neste momento da interlocução, foi perguntado aos entrevistados se poderiam iniciar o ensino da Física por Eletricidade. Uma questão pragmática, portanto, por se referir diretamente ao fazer legítimo, que permitiria apreender os significados da disciplina em sua amplitude. Esse tipo de questão evita aquela que induz a produção de um discurso ontológico, como "o que é isto?”. A pertinência da questão pragmática fica evidenciada pelos discursos que apresentaremos a seguir.

As entrevistas e suas gravações tiveram duração entre 1 e 2 horas, cada uma. Suspendemos a coleta de dados quando verificamos que havia alto grau de redundância nas respostas, ou seja, quando observamos poucas diferenças nos discursos apresentados pelos professores.

Utilizamos a análise categorial temática por ser adequada ao estudo das representações sociais, pois procura identificar os núcleos de sentido de uma comunicação "cuja presença, ou freqüência de aparição, pode significar alguma coisa para o objetivo analítico escolhido" (BARDIN, 1977, p. 105). Além disso, o tema consiste de uma unidade de registro comumente usada nos estudos que envolvem atitudes, valores, opiniões, entre outros tipos de motivações sociais. Os critérios para a avaliação dos dados tiveram, por índice de referência, o tema, e o indicador escolhido foi a presença/ausência do tema. Com base nos discursos dos professores expressos nas entrevistas realizadas - as quais foram transcritas ipsis verbis no programa de documentação de texto Data Collector (para HyperCard, Macintosh) -, teve início o processo de análise com a leitura flutuante do material. O processo de codificação foi feito a partir do recorte dos textos em unidades de registro, as quais foram enumeradas para se chegar a uma correspondência entre a presença/ausência daquelas unidades e as variáveis inferidas (significações), completando-se com a classificação desses elementos, constituindo-se, assim, um sistema de categorias baseado em critérios semânticos ou análise categorial temática. As mensagens foram inseridas em cartões interativos que permitiram trabalhar com palavras-chave, temas ou índices demarcados no próprio texto, facilitando sua categorização a qualquer momento. Os elementos categoriais, identificados pela análise categorial temática, são os da representação, na medida em que dão significados a um discurso estruturado. 
Silva, A. M. T. B.; Mazzotti, T. B.

\section{Resultados}

\section{Representação de ciência}

Os resultados desta pesquisa mostraram duas representações das ciências, em geral, e da Física, em particular. Uma delas corresponde a um pequeno grupo dos professores entrevistados (6-7\%), o qual se apoia no realismo crítico, ou seja, nas conquistas da epistemologia contemporânea. Por esta concepção, a realidade existe e só pode ser apreendida de maneira aproximada. O realismo crítico considera a Física como uma ciência ou conhecimento validável acerca do real, mas sem se comprometer nem com uma cosmovisão, nem com a relação biunívoca entre os modelos e o real. A outra constitui a posição hegemônica - em torno de 90\% dos entrevistados -, e é a que denominamos realismo ingênuo. Nesta representação a Física é uma cosmovisão, uma visão do mundo perfeitamente sistematizada, que tem suas evidências no mundo empírico, também denominado real, do qual é a expressão direta.

a) realismo crítico

A seguir apresentamos alguns extratos das falas que identificamos ser expressão do realismo crítico.

"teorias têm limites, ... acabar é com o mito de que tudo...que eu vou conseguir uma coisa que explica tudo, ... a tal da teoria unificadora e trabalhar em cima do mito que finalmente um dia eu vou conseguir aqui uma teoria que vai explicar tudo".

A fala anterior é complementada:

"ele vai construir modelos, os modelos exatamente se encadeiam entram em crise e geram o próximo modelo ... eu vou criar um modelo mecânico, ele entra em crise, ele perde o seu poder explicativo, ... não quer dizer que eu vá um dia conseguir uma teoria que não tem limite, que tudo explica, que talvez seja uma idealização, e como idealização talvez. nunca seja alcançada".

Os elementos presentes neste discurso aproximam-se de uma visão contemporânea de ciência defendida pelo racionalismo crítico: a discussão do poder preditivo de uma teoria no desenvolvimento do pensamento científico, os limites dos modelos científicos determinando as crises e as ultrapassagens (GEWANDSZNAJDER, 1995) e a consequente impossibilidade de se ter uma teoria unificadora, ou seja, uma teoria com uma abrangência explicativa de toda a ciência ou, mesmo, de toda a ciência Física.

Uma possível nuança dessa representação, identificada em uma das entrevistas, que também se aproxima de uma concepção realista da ciência Física, apresenta-se estruturada em torno dos seguintes elementos: a impossibilidade de se compreender a realidade em sua totalidade; o conhecimento como algo a ser alcançado de forma aproximativa; os modelos como limites do conhecimento. Como afirma o professor:

\footnotetext{
"a Física é algo que vai empobrecer a realidade ... quer dizer a Física não consegue jamais entender a realidade na sua totalidade, é impossivel, mas é que você deve ter condições de ao empobrecer a realidade para compreender, perceber que esse empobrecimento traz um aprofundamento também da sua visão de realidade".
} 
A Física pelos professores de Física: ...

Outra formulação desta representação é encontrada nas seguintes afirmações:

"O que eu entendo por ciência física? Olha, eu entraria mais no campo que é do seguinte teor, se você trabalha, se você tem uma realidade objetiva como parte geral de um processo universal. Quer dizer, você tem um universo, todo ele existindo, não tem a menor dúvida idealista em relação a essa questão. E existem relações objetivas nesse universo ... Então desse universo, o homem, com sua característica de ser objeto autor/ ator, ator e autor, ser o objeto modificador, o objeto que modifica, ele tenta aprender essa realidade, ele tenta aprender essa realidade. Nesse tentar de aprender a realidade ele procura ver como essas relações se comportariam. (...) É evidente que quando o homem se apropria disso ele se apropria de um modelo construído dentro de uma limitação até pelo fato de a sua presença ser um elemento modificador desse próprio modelo".

Em outro momento do discurso...

"existe alguns conceitos que são conceitos fundamentais então esses conceitos são apresentados para entendimento deles ... não há aquela seqüência tradicional da cinemática, estática, dinâmica... essa é a nossa idéia... sempre um bloco de conceitos, um bloco de conceitos, e um conjunto de expressões que permitiram a operacionalização desses conceitos e esse próximo objetivo ali mesmo que é conceituar, que é operacional em termos numéricos".

Novamente, o discurso acima representa uma posição crítica sobre a ciência física, inclusive destacando a contraposição a uma posição idealista de se olhar à realidade. Entretanto, o que configura uma estrutura diferenciada nesse discurso é a questão dos conceitos fundamentais em torno dos quais se desenvolveria a discussão do conteúdo. Essa maneira de pensar - no caso, o ensino de Física -, se aproxima da forma como Holton (1982) compreende o desenvolvimento do pensamento científico, ao redor de temas ou themata historicamente recorrentes, guiando ao conflito e à construção de teorias. Não existiriam conceitos melhores ou piores, não haveria uma ordem privilegiada de se ensinar a Física, ou seja, a sequência do livro didático não seria única, nem a mais adequada à aprendizagem; porém, um grupo de conceitos considerados básicos, no sentido de estarem de forma permanente envolvidos nos vários momentos da disciplina, ou nos modelos e teorias ensinados, seriam eleitos como nucleadores do desenvolvimento curricular, facilitando, inclusive, uma discussão interdisciplinar ou, como se argumenta a partir desta representação, a integração do conteúdo.

"Eu estou dando onda mecânica. Ai eu tenho um parceiro bom de artes plásticas, de educação artística [...]. Ele vai conseguir fazer com aquela brincadeira na corda vibrante com que os alunos tenham uma manifestação artística de pintura, de jogar aquela corda vibrante no plano. Então eles começam a querer harmônicos, eles começam a buscar harmônicos na corda vibrante para o desenho deles... [...] Há uma integração maior. Isso permitiria você crescer fora da perspectiva meramente técnica”. $[\ldots]$ 
Silva, A. M. T. B.; Mazzotti, T. B.

b) realismo ingênuo

A análise dos resultados nos apresentou outra representação e com maior adesão dos professores entrevistados: a do realismo ingênuo. Julgamos ser uma representação social, ainda que pareça ser uma opinião sobre a Física, já que os elementos dos discursos não se apresentam, imediatamente, estruturados. No entanto, como veremos, há uma estruturação forte que nos levou a considerar que os professores aderem ao realismo ingênuo.

A quase totalidade dos professores entrevistados refere-se às várias Físicas que constituem a disciplina escolar Física. Entretanto, olhando de maneira mais cuidadosa, observa-se que reportam às várias Físicas exclusivamente no âmbito do programa curricular. Por exemplo, limitam-se aos vários domínios que estruturam a sequência dos principais livros didáticos utilizados nas escolas públicas de nível médio: Mecânica, Termologia, Ótica, Eletricidade, Ondas. Ou em um desses grandes tópicos, como no caso da Mecânica: Cinemática, Dinâmica, Estática. Ou, ainda, se referem aos modelos teóricos ou Físicas - conhecidas por Física de Aristóteles, Física de Newton ou Física de Einstein, sendo que, nestes casos, nos quais ocorrem as passagens de sistemas, elas são discutidas como transições lineares e acumulativas. Poder-se-ia supor que se trata de opiniões, porém é uma representação por ser um discurso estruturado em torno de elementos comuns do realismo ingênuo. Comecemos a caracterizar o realismo ingênuo por meio de extratos dos discursos dos professores. Inicialmente, vamos examinar a concepção de história da Física, caracteristicamente linear e acumulativa:

'É, essa visão de ciência então através da Física, ... é uma visão da compreensão da natureza, dos modelos, das Físicas bem anteriores, das Físicas... da Física que a gente estuda, é a gente calcar que desde os primórdios quando se tem essa palavra Física aplicada, desde o tempo dos gregos ou anterior e já se tentava justificar as coisas que acontecem na natureza, e o que chamamos de fenômeno, os acontecimentos da natureza segundo uma certa visão, então essa segundo uma certa visão pode ser uma visão Física."

Em outro trecho do discurso:

"...mostrando que é uma ciência que ela tem... de privilegiado, como sendo da natureza bate com todas, ... quer dizer uma ciência que aborda todas as ciências pelo objeto dela, o objeto do universo...esse modo um pouco positivista de classificações do primeiro, mas eu acho que a Física está por ai, envolve todas elas, eu acho que é uma das mais antigas se tiver qualificação de antiguidade”.

A posição na qual a ciência física é apresentada como a primeira, como uma das mais antigas, perpassando todas as outras, contrapõe-se à visão da existência de níveis diversos de explicações que envolvem um determinado fenômeno, ou seja, os vários modos de organização das ciências estabelecidos pelas formalizações que foram desenvolvidas até aqui. A própria ciência Física, em particular, identificada com a natureza ou representada por meio da eleição da natureza como seu objeto, acaba sendo coisificada ou tratada, na maioria dos casos, como um grande modelo unificado que busca a compreensão da natureza considerada também como um todo homogêneo e indivisível.

Uma parte significativamente grande dos professores, cuja maioria pertence à rede estadual - algo em torno de 85\% -, utiliza palavras e expressões que representam uma posição 
não histórica sobre a ciência Física. Esta concepção sustenta-se em uma noção de ciência como explicação de tudo e do todo. A natureza, o universo, a realidade, o cotidiano, a vida aparecem nos discursos como sinônimos de um todo indivisível e homogêneo, justificando a compreensão da Física como uma ciência unificada e unificadora que conhece o todo. Mais ainda, este conhecimento é a expressão fiel daquele todo. Isso significa dizer que a ciência Física apresenta-se como um sistema completamente formalizado, com sua sequência de axiomas e teoremas, que explica o universo por ser sua expressão. $O$ realismo ingênuo supõe tal correspondência e considera que o conhecimento apresentado em sua sequência axiomática é a expressão mesma do real.

c) desfalques, distorções e suplementações

Podemos dizer que os professores desfalcam a teoria newtoniana de sua geometria, distorcem o conceito de energia da Física contemporânea e suplementam a Física com valores. Deixamos, aqui, de apresentar a exposição que mostra que há desfalque da geometria na apresentação da teoria newtoniana, a única declaradamente ensinada, bem como as razões pelas quais dizemos que distorcem o conceito de energia. Ficaremos com um aspecto: o da suplementação de valores no ensino da Física.

A Física é uma disciplina valorizada nas escolas por sua dificuldade real ou aparente, mas questionada pelos estudantes, que sempre perguntam aos professores: por que temos de estudar Física se não seremos engenheiros? Esses fins estariam ligados aos ganhos tecnológicos que, em última análise, refletiriam a necessidade tranquilizadora de uma imagem unificada do cosmos. Nesse caso, como foi discutido por Mazzotti (1997) em sua pesquisa sobre a representação social de problema ambiental, os professores suplementam o ensino de Física com valores éticos que se pretendem universais. Essa suplementação ética, bastante difundida, sustentada por cerca de $80 \%$ dos entrevistados, pode ser ilustrada pelos seguintes extratos:

\begin{abstract}
"Eu acho que a gente precisa realmente é pensar cientificamente como melhorar a vida no planeta de uma maneira mais racional, menos obcecado pelo poder, pelo poder econômico. Então eu acho que a Física aí como ciência poderia ser a palavra maior para orientar as medidas a serem tomadas pela bumanidade..."

"a Física é uma ciência que está ligada ao dia a dia. São fenômenos físicos que acontecem na natureza e que a gente tem que estudar, analisar, discutir para buscar uma vida melhor para o dia a dia da gente. Quer dizer, usá-la para melhorar a vida do ser bumano ... dentro da medicina, dentro da tecnologia em geral".

"Eu acho Física como ciência uma das partes mais importantes do universo. Várias coisas que se descobriram que se descobre até hoje vem da Física. Então eu acho a ciência física muito importante para tudo que se faz no nosso cotidiano.”
\end{abstract}

A direção ética atribuída à Física, de uma ciência que pode e deve nortear nossas relações com a natureza (a vida) e com os homens (a sociedade), orienta a cosmovisão que considera que "tudo está relacionado com tudo". Essa noção é, de fato, uma retomada da cosmovisão pré-moderna, que conduz a pensar ser possível compreender o universo/cosmos por meio do microcosmos, este imediato, ao qual temos acesso por meio dos sentidos, das sensações. Essa ideia do macrocosmos contido no microcosmos - Bacon e Comênio, por 
Silva, A. M. T. B.; Mazzotti, T. B.

exemplo, partilhavam deste modo de ver -, faz da experiência imediata a via de ascese mística (YATES, 1983; ROSSI, 1989). Por certo, a suplementação ética se põe como necessária na prática educativa, caso contrário, os estudantes não perceberão as razões pelas quais devem estudar tal disciplina. O questionável são as razões apresentadas pela maioria dos professores: elas nos levam a pensar que a Física é uma ciência unificada e unificadora do mundo, quando toda a história da Física foi e é um embate contra tais concepções totalizantes e totalitárias.

\section{Concluindo}

As teorias de mudança conceitual têm-se mostrado insuficientes para explicar e promover a aprendizagem dos conceitos científicos. A proliferação de teorias é uma evidência dessa inadequação, e as críticas constituem outra evidência da incapacidade em se resolver o problema do ensino das ciências. Centradas nas concepções alternativas dos estudantes, consideradas como "misconceptions", ou seja, concepções errôneas, essas teorias reproduzem as posições do Cognitivismo Social, sem se preocupar com a origem ou os motivos da permanência de tais concepções, nem em considerar o papel dos professores e demais difusores das ciências.

Neste trabalho apresentamos a contribuição da teoria das representações sociais para o alargamento das investigações sobre as concepções prévias, ultrapassando as posições do Cognitivismo Social. Por essa via, pode-se ver um ator ausente na literatura: o professor. Mais ainda, discutimos sobre a importância de que as pesquisas referentes às concepções alternativas e mudança conceitual devam considerar o papel das representações das ciências presentes nos livros didáticos e as apresentadas pelos professores.

As representações dos professores coordenam suas práticas educativas e consistem em fonte das distorções, desfalques e suplementações que os estudantes apresentam. Caso seja assim mesmo e este quadro se mantenha inalterado no atual cenário educacional, então será preciso rever a formação de professores de Física, uma vez que eles são os agentes da educação científica. Não basta realizar cursos de aperfeiçoamento e atualização em conteúdos da Física, são necessários projetos de intervenção que conduzam a uma análise crítica das representações sociais de ciência - neste caso, de modo particular, da ciência Física, apresentada pelos professores. E isto em todas as instâncias de formação.

\section{Referências}

BARDIN, L. Análise de conteúdo. Lisboa: Edições 70, 1977.

DISESSA, A. A. Unlearning aristotelian Physics: a study of knowledge-based learning.

Cognitive Science, Norwood/Massachusetts, v. 6, n. 1, p. 37-75, 1982.

Phenomenology and the evolution of intuition. In: GETNER, D.; STEVENS, A.

L. (Eds.). Mental models. Hillsdale/New Jersey: Lawrence Erlbaum Associates, 1983.

p. 49-70.

526

Ciência \&̊ Educação, v. 15, n. 3, p. 515-528, 2009 
A Física pelos professores de Física: ...

. Learning about knowing. In: KLEIN, E. L. (ed.) Children and Computers. New Directions for Child Development Series, n 28. São Francisco: Jossey-Bass, p. 97-125, 1985.

Knowledge in pieces. In: FORMAN, G.; PUFALL, P. (Eds.). Constructivism in the computer age. Hillsdale/New Jersey: Lawrence Erlbaum Associates, 1988. p. 49-70.

. Toward an epistemology of Physics. Cognition and instruction, Mahwah/New Jersey, v. 10, n. 2/3, p. 105-225, 1993.

DOISE, W. Cognições e representações sociais: a abordagem genética. In: JODELET, D. (Org.). As representações sociais. Rio de Janeiro: EdUERJ, 2001. p. 301-320.

DRIVER, R.; EASLEY, J. Pupils and paradigms: a review of literature related to concept development in adolescent science students. Studies in Science Education, Leeds/ Yorkshire, v. 5, n. 1, p. 61- 84, 1978.

GEWANDSZNAJDER, F. A aprendizagem por mudança conceitual: uma crítica ao Modelo PSHG. 1995. 235f. Tese (Doutorado em Educação) - Faculdade de Educação, Universidade Federal do Rio de Janeiro, Rio de Janeiro, 1995.

GILLY, M. As representações sociais no campo da Educação. In: JODELET, D. (Org.). As representações sociais. Rio de Janeiro: EdUERJ, 2001. p. 321-341.

HASHWEH, M. Z. Toward an explanation of conceptual change. European Journal of Science Education, London, v. 8, n. 3, p. 229-249, 1986.

HEWSON, M. G.; HEWSON, P. W. Effects of instruction using students' prior knowledge and conceptual change strategies on science learning. Journal of Research in Science Teaching, London, v. 20, n. 8, p. 731-743, 1983.

HEWSON, P. W.; HEWSON, M. G. An appropriate conception of teaching science: a view from studies of science learning. Science Education, New York, v. 72, n. 5, p. 597-614, 1988.

HOLTON, G. Ensayos sobre el pensamiento científico en la época de Einstein. Madrid: Alianza Editorial, 1982.

JODELET, D. Representações sociais: um domínio em expansão. In: (Org.). As representações sociais. Rio de Janeiro: EdUERJ, 2001. p. 17-44.

MAZZOTTI, T. B. Representação social de 'Problema Ambiental': uma contribuição à Educação Ambiental. Relatório de Pesquisa (Final)/CNPQ. UFRJ/CFCH - Faculdade de Educação/Laboratório do Imaginário Social e Educação, 1997.

MAZZOTTI, T. B.; OLIVEIRA, R. J. Ciência(s) da Educação. Rio de Janeiro: DP\&A, 2000.

MOSCOVICI, S. A representação social da Psicanálise. Rio de Janeiro: Zahar Editores, 1978.

. On social representation. In: FORGAS, J. P. (Ed.). Social cognition: perspectives on everyday understanting. Londres: Academic Press, 1981. p. 181-209. 
Silva, A. M. T. B.; Mazzotti, T. B.

The phenomenon of social representations. In: FARR, M.; MOSCOVICI, S. (Eds.). Social representations. Paris: Maison des Sciences de l'homme/Cambridge University Press, 1984. p. 3-69.

Notes towards a description of social representations. European Journal of Social Psychology, Chichester/Sussex, v. 18, n. 3, p. 211-250, 1988.

. Das representações coletivas às representações sociais. In: JODELET, D. (Org.). As representações sociais. Rio de Janeiro: EdUERJ, 2001. p. 45-66. 2003.

Representações sociais: investigações em Psicologia Social. Petrópolis: Vozes,

PIAGET, J.; GARCIA, R. Psicogénese e História das Ciências. Lisboa: Publicações Dom Quixote, 1987a.

Vers une logique des siginifications. Géneve: Mourionde Editeur, 1987b.

POSNER, G. J. et al. Accommodation of a scientific conception: toward a theory of conceptual change. Science Education, New York, v. 66, n. 2, p. 211-227, 1982.

POSNER, G. J.; STRIKE, K. A. Conceptual change and science teaching. European Journal of Science Education, London, v. 4, n. 3, p. 231-240, 1982.

ROSSI, P. Os filósofos e as máquinas: 1400-1700. São Paulo: Cia. das Letras, 1989.

SÁ, C. P. Representações sociais: o conceito e o estado atual da teoria. In. SPINK, M. J. P. (Org.). O conhecimento no cotidiano: as representações sociais na perspectiva da teoria da Psicologia Social. São Paulo: Brasiliense, 1995. p. 19-45.

A construção do objeto de pesquisa em representações sociais. Rio de Janeiro: EdUERJ, 1998.

SMITH, J. P. III; DISESSA, A. A.; ROSCHELLE, J. Misconceptions reconceived: a constructivist analysis of knowledge in transition. The Journal of the Learning Sciences, Hillsdale/New Jersey, v. 3, n. 2, p. 115-163, 1993.

STRIKE, K. A.; POSNER, G. J. A revisionist theory of conceptual change. In: DUSCHL, R. A.; HAMILTON, R. J. (Eds.). Philosophy of Science, Cognitive Psychology and Educational Theory and Practice. Albany: State University of New York Press, 1992. p. $147-176$.

VIENNOT, L. Spontaneous reasoning in elementary dynamics. European Journal of Science Education, London, v. 1, n. 2, p. 205-221, 1979.

YATES, F. A. O iluminismo Rosa-Cruz. São Paulo: Pensamento, 1983.

Artigo recebido em novembro de 2008 e aceito em novembro de 2009. 